\title{
Type 2 diabetes gene TCF7L2 polymorphism is not associated with fetal and postnatal growth in two birth cohort studies Dennis O Mook-Kanamori ${ }^{\dagger 1,2,3}$, Sandra WK de Kort ${ }^{\dagger 3}$, Cornelia M van Duijn$^{2}$, Andre G Uitterlinden ${ }^{2,4}$, Albert Hofman², Henriëtte A Moll², Eric AP Steegers ${ }^{5}$, Anita CS Hokken-Koelega ${ }^{3}$ and Vincent WV Jaddoe ${ }^{* 1,2,3}$
}

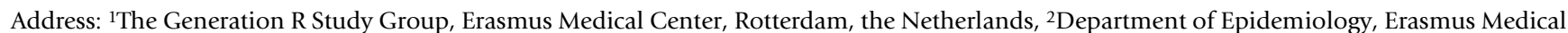 \\ Center, Rotterdam, the Netherlands, ${ }^{3}$ Department of Pediatrics, Erasmus Medical Center, Rotterdam, the Netherlands, ${ }^{4}$ Department of Internal \\ Medicine, Erasmus Medical Center, Rotterdam, the Netherlands and ${ }^{5}$ Department of Obstetrics \& Gynecology, Erasmus Medical Center, \\ Rotterdam, the Netherlands \\ Email: Dennis O Mook-Kanamori - d.mook@erasmusmc.nl; Sandra WK de Kort - s.dekort@erasmusmc.nl; Cornelia M van \\ Duijn - c.vanduijn@erasmusmc.nl; Andre G Uitterlinden - a.g.uitterlinden@erasmusmc.nl; Albert Hofman - a.hofman@erasmusmc.nl; \\ Henriëtte A Moll - h.a.moll@erasmusmc.nl; Eric AP Steegers - e.a.p.steegers@erasmusmc.nl; Anita CS Hokken- \\ Koelega - a.hokken@erasmusmc.nl; Vincent WV Jaddoe* - v.jaddoe@erasmusmc.nl \\ * Corresponding author †Equal contributors
}

Published: 17 July 2009

BMC Medical Genetics 2009, 10:67 doi:10.1 186/1471-2350-10-67
Received: 24 March 2009

Accepted: 17 July 2009

This article is available from: http://www.biomedcentral.com//47/-2350/10/67

(C) 2009 Mook-Kanamori et al; licensee BioMed Central Ltd.

This is an Open Access article distributed under the terms of the Creative Commons Attribution License (http://creativecommons.org/licenses/by/2.0), which permits unrestricted use, distribution, and reproduction in any medium, provided the original work is properly cited.

\begin{abstract}
Background: An inverse association between birth weight and the risk of developing type 2 diabetes (T2D) in adulthood has been reported. This association may be explained by common genetic variants related to insulin secretion and resistance, since insulin is the most important growth factor in fetal life. The objective of this study was to examine whether T2D gene polymorphism TCF7L2 rs7903।46 is associated with growth patterns from fetal life until infancy.
\end{abstract}

Methods: This study was performed in two independent birth cohort studies, one prospective population-based (Generation R), and one of subjects born small-for-gestational-age (SGA cohort). Fetal growth was assessed by ultrasounds in second and third trimesters of pregnancy in Generation R. Growth in infancy was assessed in both cohorts at birth and at 6, 12 and 24 months postnatally. TCF7L2 genotype was determined in 3,419 subjects in Generation R and in 566 subjects in the SGA cohort.

Results: Minor allele frequency did not differ significantly $(\mathrm{P}=0.47)$ between Generation R (Tallele: $28.7 \%$ ) and the SGA cohort (T-allele: $29.8 \%$ ). No differences at birth were found in gestational age or size (head circumference, length, weight) between the genotypes in either cohort. TCF7L2 genotype was also not associated with any pre- or postnatal growth characteristic in either Generation R or the SGA cohort.

Conclusion: We found no evidence for an association between TCF7L2 genotype and fetal and early postnatal growth. Furthermore, this TCF7L2 polymorphism was not associated with an increased risk of SGA. 


\section{Background}

Several epidemiological studies have shown inverse associations between birth weight and metabolic diseases, including type 2 diabetes (T2D) in adulthood $[1,2]$. These associations may be influenced by common genetic variants [2]. Insulin is the most important fetal growth factor and insulin-mediated fetal growth might be affected by genetic polymorphisms that regulate fetal insulin secretion or insulin sensitivity [2]. Therefore, gene variants associated with T2D have been suggested as candidate genes for influencing early growth [2].

Genome-wide association (GWA) studies have consistently shown that the C>T substitution in TCF7L2 gene (rs7903146) increases the risk of T2D approximately 2fold when two risk allele copies (TT) are present [3-5]. The T-allele of this TCF7L2 polymorphisms has been suggest to reduce proinsulin to insulin conversion [6], though the exact mechanism has not been elucidated yet. Other single nucleotide polymorphisms (SNPs) of the TCF7L2 gene have been shown to be associated with type 2 diabetes, although less strongly [7]. The T-allele of rs7903146, which according to HapMap has an allele frequency amongst Caucasians (CEU) of 28\% [8], has been shown to be associated with reduced insulin response and secretion in both diabetic and non-diabetic individuals [9-11], though results in non-diabetics are not consistent [12]. This polymorphism may also lead to an increased risk of gestational diabetes [13]. Such findings make TCF7L2 one of the most important candidate genes for explaining the associations between low birth weight and T2D.

Freathy et al. were the first to investigate the association between TCF7L2 genotype and birth weight, and they found an association with maternal TCF7L2 genotype [14]. Each maternal copy of the risk allele was associated with a 30 grams increase in offspring birth weight, probably as a result of higher maternal glucose levels stimulating fetal insulin production [14]. After adjustment for maternal genotype, fetal TCF7L2 genotype did not influence fetal birth weight [14]. This finding was replicated in the Helsinki birth cohort [15]. In another study, no association was found between fetal TCF7L2 genotype and the risk of small size for gestational age [16]. Birth weight might be an inappropriate measure of the individual growth potential since different fetal growth rates may lead to the same birth weight [17]. Furthermore, rapid postnatal weight gain, especially in fat mass, has also been shown to be associated an increase risk of obesity and type 2 diabetes in later life, independent of birth weight $[18,19]$.

Therefore we hypothesized that longitudinally measured fetal and postnatal growth are better parameters in the investigation of the possible effect of TCF7L2 on growth than specific growth characteristic such as birth weight.
We first assessed the associations of TCF7L2 rs7903146 with fetal and postnatal growth characteristics in a population-based prospective cohort study among 3,419 subjects followed from early fetal life onwards. Second, we assessed associations of this genotype with birth weight and postnatal growth in 566 small-for-gestational-age (SGA) children participating in an independent cohort study.

\section{Methods \\ Cohort Descriptions \\ The Generation R Study}

The Generation R Study is a population based prospective cohort study from early fetal life onwards. The study is designed to identify early environmental and genetic determinants of growth, development and health from fetal life until young adulthood. It has been described previously in detail $[20,21]$. Fetal and postnatal growth and their main determinants were repeatedly measured by physical examinations, fetal ultrasounds, biological samples and questionnaires. We have previously shown that of all eligible children born in the study area $61 \%$ participated in the study [21]. The study has been approved by the Medical Ethics Committee of the Erasmus Medical Center, Rotterdam. Written informed consent was obtained from all participants or their parents.

\section{Fetal growth and birth characteristics}

Fetal ultrasound examinations were carried out during visits to one of the research centers. These fetal ultrasounds were used for establishing gestational age in the first trimester of pregnancy (conception to 12 weeks of gestational age), as well as for assessing fetal growth characteristics in second (17-25 weeks of gestational age) and third trimesters ( $>25$ weeks of gestational age) of pregnancy [22]. Fetal growth measurements used in the present study included head circumference (HC), abdominal circumference (AC) and femur length (FL) measured in second and third trimesters to the nearest mm using standardized ultrasound procedures [23]. Estimated fetal weight (EFW) was calculated by means of the formula from Hadlock using head circumference, abdominal circumference and femur length $\left(\log _{10} \mathrm{EFW}=1.5662-\right.$ $0.0108(\mathrm{HC})+0.0468(\mathrm{AC})+0.171(\mathrm{FL})+0.00034(\mathrm{HC})^{2}$ $-0.003685(\mathrm{AC} * \mathrm{FL}))$ [24]. First trimester ultrasound measures were not included for assessing growth characteristics because these ultrasound examinations were primarily performed to establish gestational age.

\section{Birth and postnatal growth}

Birth weight, date of birth and gender were obtained from community midwife and hospital registries. Information on head circumference or length at birth was not available, but many children were measured during the first two months of life. Well-trained staff in community health centers obtained postnatal growth characteristics using 
standardized procedures. Based on the routine health care program, the visits at which these growth characteristics were measured were grouped into three age periods: 6 months (range 5 to 8.99 ); 12 months (range 9 to 12.99 ); and 24 months (range 23 to 34.99 months). Postnatally, head circumference was not measured at the age of 24 months.

\section{Population for analysis}

Analyses were restricted to singletons from whom DNA was available for TCF7L2 genotyping and who also had Dutch or other Caucasian ethnicity as defined by having both parents born in the Netherlands or another European country $(n=3,419)$ (Figure 1$)$. Fetal growth measurements were available for 3,320 and 3,384 children in second and third trimesters, respectively. Of these children, those living outside the study area postnatally $(10 \%)$ were not followed up in infancy and a further $12 \%$ were lost during postnatal follow-up, leaving 2,675 subjects eligible for the postnatal analyses (Figure 1).

\section{The SGA Cohort}

The SGA cohort was designed for the purpose of assessing growth and development of subjects born SGA. Subjects were included at childhood age $(n=367)$ or at young adult age $(n=252)$. Children were included in the SGA cohort when they were SGA at birth, had short stature (height standard deviation score (SDS) for age and gender of below - 2 [25]), did not show catch-up growth in height, and had no growth failure caused by any other identified disorder. These inclusion criteria have previously been described [26]. Young adults included in the SGA cohort were randomly selected from hospitals in the Netherlands, where they had been registered because of being SGA. Only those young adults born at 36 weeks or more of gestation, being singleton and Caucasian and not suffering from conditions or receiving treatment known to interfere with growth, were invited to participate. SGA was defined as a birth length and/or birth weight SDS of below -2.0 for gestational age [27]. The Medical Ethics Committees of Erasmus Medical Center, Rotterdam, and of the participating centers approved all studies and written informed consent was obtained from all participants or their parents.

\section{Birth and postnatal growth}

Birth characteristics of the SGA cohort were collected from hospital registries. The gestational age of the subjects was determined by ultrasound in the first trimester, if available, and otherwise calculated from the date of the last menstruation. Growth data (head circumference, height and weight) measured during the first two years of life were collected from records of hospitals, community health services and general practitioners. Longitudinal growth data were available in 272 participants in the SGA cohort (Figure 1).

\section{Genotyping}

DNA was collected from cord blood samples in the Generation R cohort and from peripheral venous blood samples in the SGA cohort. Cord blood for DNA isolation was available for $59 \%$ of all participating children of the Generation $\mathrm{R}$ cohort. When cord blood samples were missing, this result was mainly due to logistical constraints at the delivery. Venous blood samples were available in the complete SGA cohort. Genotyping of the C>T substitution in TCF7L2 (rs7903146) gene was performed using Taqman allelic discrimination assay (Applied Biosystems, Foster City, CA) and Abgene QPCR ROX mix (Abgene, Hamburg Germany). The genotyping reaction was amplified using the GeneAmp ${ }^{\circledR}$ PCR system $9600\left(95^{\circ} \mathrm{C}(15\right.$ minutes), with 40 cycles of $94^{\circ} \mathrm{C}$ (15 seconds) and $60^{\circ} \mathrm{C}$ (1 minute)). The fluorescence was detected on the 7900HT Fast Real-Time PCR System (Applied Biosystems)
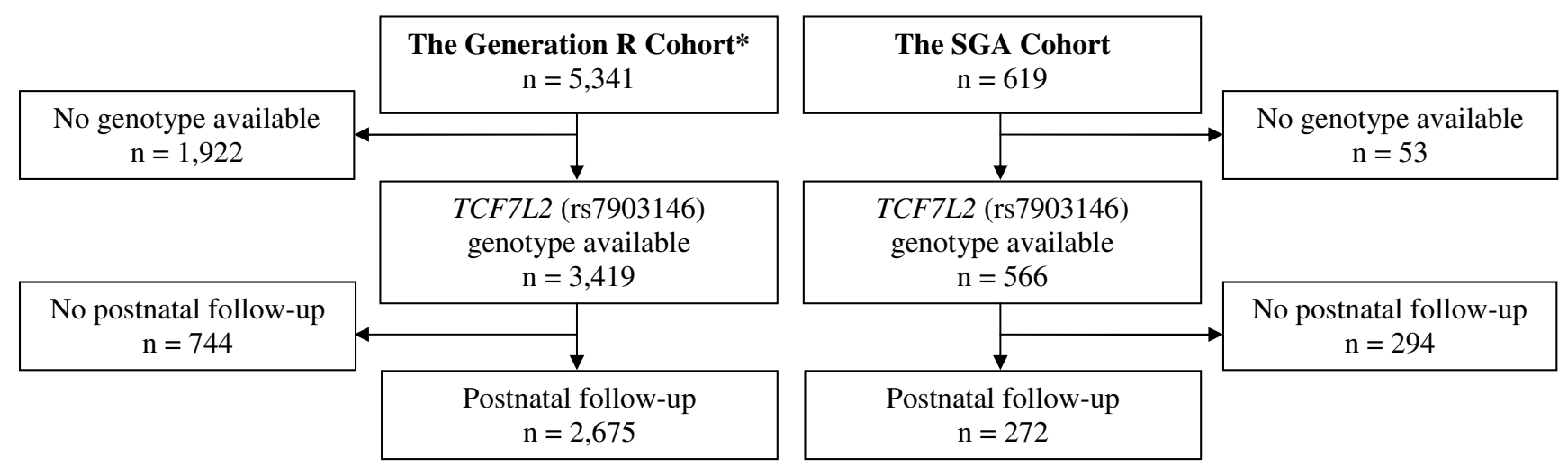

Figure I

Flow diagram indicating number of subjects in the two cohorts. * All live-born, Caucasian, singleton subjects within Generation R. 
and individual genotypes were determined using SDS software (version 2.3, Applied Biosystems). Genotyping was successful in $98 \%$ and $91 \%$ of the samples in the Generation R and SGA cohort, respectively. To confirm the accuracy of the genotyping results, 276 randomly selected samples from the Generation R Study were genotyped for a second time with the same method. The error rate was less than $1 \%$. The frequency distribution in Generation $\mathrm{R}$ did not deviate from the Hardy-Weinberg equilibrium in subjects with Dutch ethnicity nor did it deviate in the SGA cohort.

\section{Data analysis}

With sample sizes in the Generation R Study of 3,419 and 2,675 subjects for fetal and postnatal analyses respectively, and assuming a statistical power level $(1-\beta)$ of 0.80 , a level of significance $(\alpha)$ of 0.05 and a variance of 1.0 , we were able to detect differences in growth characteristics of 0.048 SDS and 0.054 SDS respectively. First, differences in allele distribution between children born SGA (from the SGA cohort) and non-SGA subjects (from Generation R) were assessed. Differences were calculated using the Chi-square test. Second, we examined the differences in birth characteristics between genotype groups with linear regression analyses assuming an additive model. Weight, length and head circumference at birth and at different ages were analyzed using gender and age adjusted standard deviation scores (SDS) $[27,28]$. Standard deviation scores were obtained using Dutch reference growth curves (Growth Analyser 3.0, Dutch Growth Research Foundation). For Generation R, we used the first length SDS and head circumference SDS measured after birth and before the second month of life, since these measurements were not available at birth. Third, we compared fetal (only Generation R) and postnatal characteristics between the genotypes with linear regression analyses. Finally, to assess longitudinally measured weight and length patterns from fetal life to infancy, we performed repeated measures regression analysis in both cohorts with weight and length from birth to 24 months as outcome variables. This regression technique takes the correlation of multiple measurements within one subject into account, assesses both the time-independent and timedependent effect of TCF7L2 genotype on growth, and allows for incomplete outcome data [29]. In these models, genotype was included as both intercept and interaction with age. To account for (gestational) age at each specific measurement, these analyses were conducted with age-adjusted standard deviation scores. The models can be written as:

Height (SDS) or weight (SDS) $=\beta_{0}+\beta_{1} *$ age $+\beta_{2} *$ TCF7L2 genotype

$$
+\beta_{3} * \text { TCF7L2 genotype * age. }
$$

In this model, the term including ' $\beta_{0}{ }^{\prime}$ reflects the intercept and the term including ' $\beta_{1}$ ' reflects the slope of growth (weight or length) per week for the reference group (CC genotype). The terms including ' $\beta_{2}$ ' and ' $\beta_{3}$ ' reflect the age independent growth differences in weight (and length) between the different categories of the TCF7L2 genotype respectively [30]. All models were unadjusted (all growth characteristics are age and gender adjusted SD scores) since population genotype distribution is assumed to be unrelated to covariates and the effect estimates were not materially affected by adjusting for maternal age, prepregnancy body mass index or parity [31]. The occurrence of gestational diabetes in the entire cohort was $0.6 \%$ and did not affect the effect estimates. Therefore, occurrence of gestational diabetes was not included in the analyses.

All effect estimates are presented with their 95\% confidence interval (95\% CI). Statistical analyses were performed using the Statistical Analysis System version 9.1.3 (SAS, Stata corporation, College Station, TX, USA), including the PROC MIXED module for unbalanced repeated measurements as well as the Statistical Package of Social Sciences version 15.0 for Windows (SPSS Inc, Chicago, IL, USA).

\section{Results}

Subject characteristics of Generation R and SGA cohort are presented in Table 1 . The minor allele frequency distributions did not differ significantly ( $\mathrm{p}=0.47$ ) between nonSGA subjects (from Generation R) (T-allele: $28.7 \%$ ) and the SGA cohort (T-allele: 29.8\%) (Table 2).

No significant differences between genotype groups were observed in fetal growth characteristics in Generation $\mathrm{R}$

Table I: Subject characteristics by cohort.

\begin{tabular}{lcc}
\hline Characteristics & Generation R & The SGA cohort \\
\hline Gender (\% boys) & $50.8 \%$ & $47.2 \%$ \\
Gestational age (weeks) & $40.1(36.7-42.4)$ & $38.0(29.9-41.0)$ \\
Birth weight (grams) & $3513(511)$ & $1819(716)$ \\
Premature (gestational age < 37 weeks) (\%) & $2.9 \%$ & $44.9 \%$ \\
Birth weight < 2500 grams (\%) & $2.5 \%$ & $82.7 \%$ \\
Small for gestational age (weight <-2 SDS) (\%) & $0.9 \%$ & $100 \%$ \\
Gestational diabetes (\%) & $0.6 \%$ & N/A
\end{tabular}

Values are means (SD), medians ( $95 \%$ range) or percentages. $\mathrm{N} / \mathrm{A}=$ not available 
Table 2: Distribution of TCF7L2 rs7903 I 46 minor allele frequency according to cohort.

\begin{tabular}{lccc}
\hline \multicolumn{4}{c}{ Allele frequency } \\
\hline & C-Allele & T-Allele & p-value \\
\hline Non-SGA (Generation R) (\%) & $4828(71.3)$ & $1948(28.7)$ & \\
SGA (SGA cohort) (\%) & $795(70.2)$ & $337(29.8)$ & 0.49 \\
\hline
\end{tabular}

Non-SGA = All subjects from Generation R, excluding SGA subjects SGA = birth weight SDS and/or birth length SDS <-2

$p$-value express differences in distribution between SGA and General population tested with Chi-square test.

(Table 3). No differences in birth characteristics (head circumference, length and weight), between genotype groups were observed in either cohort (Table 4). Postnatal growth characteristics for both cohorts are shown in Table 5. No significant differences were found in either cohort for head circumference, weight or height at any age.

Finally, no differences were found in weight growth rate (SDS/year) from birth until the age of 2 years in either Generation R or the SGA cohort. Compared to the CC genotype, differences were - 0.014 (95\% confidence interval (CI): -0.064, 0.036) SDS/year and -0.028 (95\% CI: $0.057,0.002)$ SDS/year, for the CT and TT genotype, respectively, in Generation R. In the SGA cohort, differences were -0.134 (95\% CI: -0.376, 0.108) SDS/year and 0.002 (95\% CI: $-0.125,0.129)$ SDS/year, for the CT and TT genotype, respectively, using the CC genotype as a reference. Similarly, no differences were found in height growth rate from birth to 2 years in either cohort (data not shown).

\section{Discussion}

In the current study, we found that T2D gene polymorphism TCF7L2 rs7903146 is not associated with growth in fetal life in the general population or with growth in early postnatal life in either the general population or in a cohort of subjects born SGA. We also confirmed previous suggestions that this variant of TCF7L2 is not associated with birth weight and, more importantly, demonstrated that it does not influence the fetal development using direct fetal measurements. Finally, we showed that this polymorphism does not appear to be associated with the risk of being born SGA.

To our knowledge, this study is the first to examine the association of TCF7L2 with longitudinally measured growth patterns in fetal and early postnatal life in two independent birth cohorts. In the Generation R Study, DNA for genotyping was available in $59 \%$ of all subjects and was isolated from cord-blood. Missing cord-blood was mainly caused by logistical restraints at delivery. Children who were not genotyped had a shorter gestational age $(\mathrm{p}<0.001)$ and were lighter at birth $(\mathrm{p}<0.001)$ than subjects who were genotyped. Of all genotyped eligible subjects at baseline, $22 \%$ did not participate in follow-up measurements. In the SGA cohort, genotyping was successful in $91 \%$ of the subjects and longitudinally growth data were available in $48 \%$ of the cohort. Our effect estimates could be biased if the associations between genotypes and growth characteristics differed between those with and without postnatal growth data available. In the Generation $\mathrm{R}$ cohort, no differences were observed between children with and without postnatal growth measurements. In the SGA cohort the T-allele was slightly more frequent in subjects with postnatal growth measurements than in subjects without these measurements $(\mathrm{p}<$ 0.05 ). Finally, it could be possible that there is differential effect of genotype on growth according to availability of follow-up data. This bias would affect our estimates, though such a bias seems unlikely.

Several studies have investigated the effect of common genetic variants related to insulin action and secretion on early growth $[14,15,32,33]$. Of the initially identified T2D gene polymorphisms identified by the GWA, fetal CDKAL1 (rs7754840) and HHEX (rs1111875) genotype, and maternal TCF7L2 (rs7903146) genotype have been

Table 3: Fetal characteristics according to fetal TCF7L2 rs7903 I 46 genotype in the Generation R study.

\begin{tabular}{|c|c|c|c|c|}
\hline & $\begin{array}{c}C C \\
(n=1736)\end{array}$ & $\begin{array}{c}C T \\
(n=1329)\end{array}$ & $\begin{array}{c}\text { TT } \\
(n=301)\end{array}$ & p-value \# \\
\hline \multicolumn{5}{|c|}{ Fetal characteristics second trimester } \\
\hline Head circumference (SDS) & $0.04(1.0)$ & $0.02(1.0)$ & $0.05(0.9)$ & 0.88 \\
\hline Femur length (SDS) & $-0.01(1.0)$ & $-0.01(1.0)$ & $0.05(0.9)$ & 0.64 \\
\hline Estimated fetal weight (SDS) & $-0.06(1.0)$ & $-0.07(1.0)$ & $0.00(1.0)$ & 0.57 \\
\hline \multicolumn{5}{|c|}{ Fetal characteristics third trimester } \\
\hline Head circumference (SDS) & $0.11(1.0)$ & $0.13(1.0)$ & $0.15(0.9)$ & 0.45 \\
\hline Femur length (SDS) & $0.01(1.0)$ & $-0.02(1.0)$ & $-0.04(1.0)$ & 0.34 \\
\hline Estimated fetal weight (SDS) & $0.12(1.0)$ & $0.14(1.0)$ & $0.11(0.9)$ & 0.99 \\
\hline
\end{tabular}

Values are means (SD). SDS = standard deviation score for age and gender.

\# $\mathrm{p}$-values for additive models. Differences were tested using linear regression analyses. 
Table 4: Birth characteristics in both cohorts according to TCF7L2 rs7903 I 46 genotype of child.

\begin{tabular}{|c|c|c|c|c|c|}
\hline Generation $\mathbf{R}$ & & $\begin{array}{c}C C \\
(n=1762)\end{array}$ & $\begin{array}{c}C T \\
(n=|35|)\end{array}$ & $\begin{array}{c}\text { TT } \\
(n=306)\end{array}$ & p-value $\#$ \\
\hline Gestational age (weeks) & $\mathrm{n}=3419$ & $40.3(36.7-42.3)$ & $40.3(36.6-42.4)$ & $40.1(37.1-42.6)$ & 0.83 \\
\hline Birth head circumference (SDS)* & $\mathrm{n}=2314$ & $0.22(0.9)$ & $0.24(0.9)$ & $0.26(0.9)$ & 0.55 \\
\hline Birth length (SDS)* & $n=1959$ & $-0.07(1.0)$ & $-0.08(1.0)$ & $0.00(1.1)$ & 0.66 \\
\hline Birth weight (SDS) & $\mathrm{n}=3419$ & $0.21(1.0)$ & $0.22(1.0)$ & $0.20(1.0)$ & 0.97 \\
\hline SGA Cohort & & $\begin{array}{c}C C \\
(n=270)\end{array}$ & $\begin{array}{c}C T \\
(n=255)\end{array}$ & $\begin{array}{c}\text { TT } \\
(n=41)\end{array}$ & p-value $\#$ \\
\hline Gestational age (weeks) & $n=566$ & $38.0(28.6-42.0)$ & $38.0(28.6-41.0)$ & $38.0(29.0-42.0)$ & 0.57 \\
\hline Birth head circumference (SDS) & $n=203$ & $-1.51(1.4)$ & $-1.20(1.6)$ & $-1.31(1.4)$ & 0.32 \\
\hline Birth length (SDS) & $n=491$ & $-3.11(1.4)$ & $-3.27(1.5)$ & $-3.02(1.5)$ & 0.41 \\
\hline Birth weight (SDS) & $n=566$ & $-2.40(1.0)$ & $-2.46(0.9)$ & $-2.32(0.9)$ & 0.58 \\
\hline
\end{tabular}

* Length and head circumference were measured in the first two months of after birth.

Values are means (SD) or medians ( $95 \%$ range). SDS = standard deviation score for age and gender.

\# p-values for additive models. Differences were tested using linear regression analyses.

shown to affect birth weight. Pulizzi et al. demonstrated in the Helsinki Birth Cohort that fetal TCF7L2 genotype did not interact with birth weight to increase the risk of T2D in adulthood [15].TCF7L2 rs7903146 has been shown to have the strongest genetic effect on T2D and this result has been replicated in several studies [3-5]. Therefore, TCF7L2 is a very important candidate gene for explaining the association between low birth weight and T2D risk. Our study is the first to investigate the effect of TCF7L2 rs7903146 on longitudinal growth in early life. Longitudinal assess- ment of growth provides more information than just measurements at birth as we have demonstrated earlier that different fetal growth patterns may result in a similar birth weight [17]. Furthermore, most SGA born children have catch-up growth during the first months of life but $15 \%$ remain small [34]. Thus, to investigate whether TCF7L2 rs7903146 influences fetal and postnatal growth, longitudinal growth data provide more information than birth weight alone.

Table 5: Postnatal characteristics at 6, I2, and 24 months according to TCF7L2 rs7903 I 46 genotype.

\begin{tabular}{|c|c|c|c|c|c|}
\hline Generation R & & $\begin{array}{c}C C \\
(n=1375)\end{array}$ & $\begin{array}{c}C T \\
(n=1063)\end{array}$ & $\begin{array}{c}\text { TT } \\
(n=237)\end{array}$ & p-value \# \\
\hline 6 months & Head circumference (SDS) & $-0.02(0.93)$ & $-0.03(0.89)$ & $-0.06(0.91)$ & 0.83 \\
\hline \multirow[t]{2}{*}{$n=2675$} & Height (SDS) & $0.03(0.91)$ & $0.03(0.90)$ & $0.07(0.93)$ & 0.81 \\
\hline & Weight (SDS) & $0.41(0.96)$ & $0.44(0.95)$ & $0.54(0.99)$ & 0.14 \\
\hline 12 months & Head circumference (SDS) & $0.00(0.89)$ & $-0.04(0.94)$ & $-0.03(1.12)$ & 0.54 \\
\hline \multirow[t]{2}{*}{$n=2559$} & Height (SDS) & $-0.01(0.90)$ & $-0.05(0.90)$ & $-0.01(0.90)$ & 0.70 \\
\hline & Weight (SDS) & $0.18(0.98)$ & $0.18(0.99)$ & $0.24(1.00)$ & 0.63 \\
\hline 24 months & Height (SDS) & $-0.19(0.93)$ & $-0.21(0.89)$ & $-0.18(0.87)$ & 0.82 \\
\hline$n=2445$ & Weight (SDS) & $-0.11(0.99)$ & $-0.13(1.00)$ & $-0.09(0.96)$ & 0.87 \\
\hline SGA cohort & & $\begin{array}{c}C C \\
(n=143)\end{array}$ & $\begin{array}{c}C T \\
(n=107)\end{array}$ & $\begin{array}{c}\text { TT } \\
(n=22)\end{array}$ & \\
\hline 6 months & Head circumference (SDS) & $-1.38(0.92)$ & $-1.36(0.90)$ & $-1.74(1.04)$ & 0.41 \\
\hline \multirow[t]{2}{*}{$n=272$} & Height (SDS) & $-2.39(1.37)$ & $-2.43(1.26)$ & $-2.51(1.55)$ & 0.93 \\
\hline & Weight (SDS) & $-2.18(1.40)$ & $-2.22(1.26)$ & $-2.37(2.05)$ & 0.86 \\
\hline 12 months & Head circumference (SDS) & $-1.21(0.83)$ & $-1.24(0.88)$ & $-1.72(1.06)$ & 0.16 \\
\hline \multirow[t]{2}{*}{$n=268$} & Height (SDS) & $-2.25(1.25)$ & $-2.30(1.06)$ & $-2.30(1.47)$ & 0.94 \\
\hline & Weight (SDS) & $-2.14(1.4 I)$ & $-2.25(1.15)$ & $-2.17(1.89)$ & 0.82 \\
\hline 24 months & Head circumference (SDS) & $-1.10(0.82)$ & $-1.13(0.87)$ & $-1.60(1.06)$ & 0.20 \\
\hline \multirow[t]{2}{*}{$\mathrm{n}=244$} & Height (SDS) & $-2.39(1.24)$ & $-2.47(1.05)$ & $-2.94(1.04)$ & 0.20 \\
\hline & Weight (SDS) & $-2.19(1.33)$ & $-2.31(1.21)$ & $-3.06(1.65)$ & 0.04 \\
\hline
\end{tabular}

Values expressed as mean (SD). SDS = standard deviation score for age and gender.

\# $\mathrm{p}$-values for additive models. Differences were tested using linear regression. 
Freathy et al. found an increase of birth weight for each fetal and maternal risk allele [14]. They concluded that the most likely mechanism for this association was that maternal genotype was associated with a reduction of maternal insulin secretion, leading to increased fetal glucose and insulin levels and subsequently increased birth weight, rather than a direct effect of the fetal genotype on birth weight. Pulizzi et al. found no effect of the fetal genotype of this polymorphism on birth weight. Since fetal and maternal genotypes are $50 \%$ correlated, it cannot be excluded that, when the risk allele is present in both mother and child, small effects of fetal genotype that reduce fetal growth could be masked by opposing effects of maternal genotype. Since maternal genotype was not available in our study, we were not able to test this hypothesis. However, we did not find any effect of fetal genotype on birth weight in the general population nor in a specific population of children with insufficient fetal growth resulting in small size for gestational age at birth. Our findings are therefore in line with the conclusions of these previous studies. Furthermore, we found no effect of fetal genotype on estimated fetal weight or weight during infancy, indicating that there is no evidence for any association between this fetal genotype and weight or change in weight during early life either. The effect of this polymorphism on the metabolic phenotype found in adults would therefore appear to develop after early childhood. Nonetheless, our results also could be explained by a lack of power and we cannot rule out that we were unable to detect smaller effects of this variant on early growth.

Regarding intra-uterine growth retardation, an earlier study examined the effect of TCF7L2 rs7903146 genotype on SGA. Cauchi et al. found no association between this genotype and SGA, using family-based association analyses in over 3,000 subjects of which 627 subjects were SGA [16]. In this analyses, the SGA group was slightly larger than in our current study and included parents, but postnatal growth data were not analyzed longitudinally. In our study, we did not find a difference in minor allele frequency between the general population (Generation $\mathrm{R}$ ) and the SGA cohort. On the basis of two independent and negative studies, one may conclude that there is no association between this genetic polymorphism and risk of SGA.

\section{Conclusion}

In summary, our results suggest that TCF7L2 rs7903146 does not influence growth from early fetal life to infancy. Furthermore, minor allele frequency was not different in SGA subjects than in non-SGA subjects, indicating that it is unlikely that this polymorphism is associated with the risk of being born SGA. Systematic searches for common genetic variants by means of genome-wide association studies will enable us to obtain a more complete under- standing of which genes are involved in growth in fetal life and infancy.

\section{Competing interests}

The authors declare that they have no competing interests.

\section{Authors' contributions}

DOMK, SWKdK, ACSHK and VWVJ made substantial contributions to conception and design of the manuscript and the analysis and interpretation of data. CMvD and AGU were involved in the genetic analysis of the data. AH and HAM were involved in the design of the cohort. EAPS was responsible for the prenatal growth data collection. All authors were involved in drafting and revising the manuscript and have given final approval of the version to be published.

\section{Acknowledgements}

The Generation R Study is conducted by the Erasmus Medical Center in close collaboration with the School of Law and Faculty of Social Sciences of the Erasmus University Rotterdam, the Municipal Health Service Rotterdam area, Rotterdam, the Rotterdam Homecare Foundation, Rotterdam and the Stichting Trombosedienst \& Artsenlaboratorium Rijnmond (STAR), Rotterdam. We gratefully acknowledge the contribution of general practitioners, hospitals, midwives and pharmacies in Rotterdam. The first phase of the Generation R Study is made possible by financial support from the Erasmus Medical Center, Rotterdam, the Erasmus University Rotterdam and the Netherlands Organization for Health Research and Development (ZonMw). Also, we would like to thank all participants and their parents of the SGA cohort. We greatly acknowledge R.W. Leunissen, W.A. Ester, C. Bruinings-Vroombout, M. Huibregtse-Schouten, J. van Houten, J. van Nieuwkasteele, J. Dunk and E. Lems, for their assistance with data collection of the SGA subjects.

\section{References}

I. Whincup PH, Kaye SJ, Owen CG, Huxley R, Cook DG, Anazawa S, Barrett-Connor E, Bhargava SK, Birgisdottir BE, Carlsson S, et al.: Birth weight and risk of type 2 diabetes: a systematic review. Jama 2008, 300(24):2886-2897.

2. Hattersley AT, Tooke JE: The fetal insulin hypothesis: an alternative explanation of the association of low birthweight with diabetes and vascular disease. Lancet 1999 , 353(9 | 66): I 789-I792.

3. Weedon MN: The importance of TCF7L2. Diabet Med 2007, 24(10): 1062-1066.

4. Scott LJ, Mohlke KL, Bonnycastle LL, Willer CJ, Li Y, Duren WL, Erdos MR, Stringham HM, Chines PS, Jackson AU, et al.: A genomewide association study of type 2 diabetes in Finns detects multiple susceptibility variants. Science 2007, 3 | 6(5829): | 34 |- | 345 .

5. Zeggini E, Weedon MN, Lindgren CM, Frayling TM, Elliott KS, Lango H, Timpson NJ, Perry JR, Rayner NW, Freathy RM, et al.: Replication of genome-wide association signals in UK samples reveals risk loci for type 2 diabetes. Science 2007, 3 | 6(5829): | 336- | 34 | .

6. Kirchhoff K, Machicao F, Haupt A, Schafer SA, Tschritter O, Staiger $H$, Stefan N, Haring HU, Fritsche A: Polymorphisms in the TCF7L2, CDKALI and SLC30A8 genes are associated with impaired proinsulin conversion. Diabetologia 2008, 5 I (4):597-60l.

7. Helgason A, Palsson S, Thorleifsson G, Grant SF, Emilsson V, Gunnarsdottir S, Adeyemo A, Chen Y, Chen G, Reynisdottir I, et al.: Refining the impact of TCF7L2 gene variants on type 2 diabetes and adaptive evolution. Nat Genet 2007, 39(2):2 I 8-225.

8. Frazer KA, Ballinger DG, Cox DR, Hinds DA, Stuve LL, Gibbs RA, Belmont JW, Boudreau A, Hardenbol P, Leal SM, et al.: A second 
generation human haplotype map of over 3.I million SNPs. Nature 2007, 449(7 I 64):85I-86I.

9. Damcott CM, Pollin TI, Reinhart LJ, Ott SH, Shen H, Silver KD, Mitchell BD, Shuldiner AR: Polymorphisms in the transcription factor 7-like 2 (TCF7L2) gene are associated with type 2 diabetes in the Amish: replication and evidence for a role in both insulin secretion and insulin resistance. Diabetes 2006, 55(9):2654-2659.

10. Palmer ND, Lehtinen AB, Langefeld CD, Campbell JK, Haffner SM, Norris JM, Bergman RN, Goodarzi MO, Rotter Jl, Bowden DW: Association of TCF7L2 gene polymorphisms with reduced acute insulin response in Hispanic Americans. J Clin Endocrinol Metab 2008, 93(I):304-309.

II. Saxena R, Gianniny L, Burtt NP, Lyssenko V, Giuducci C, Sjogren M, Florez JC, Almgren P, Isomaa B, Orho-Melander M, et al.: Common single nucleotide polymorphisms in TCF7L2 are reproducibly associated with type 2 diabetes and reduce the insulin response to glucose in nondiabetic individuals. Diabetes 2006 55(I0):2890-2895.

12. Munoz J, Lok KH, Gower BA, Fernandez JR, Hunter GR, Lara-Castro C, De Luca M, Garvey WT: Polymorphism in the transcription factor 7-like 2 (TCF7L2) gene is associated with reduced insulin secretion in nondiabetic women. Diabetes 2006 55(I 2):3630-3634.

13. Shaat N, Lernmark A, Karlsson E, Ivarsson S, Parikh H, Berntorp K, Groop $L$ : A variant in the transcription factor 7-like 2 (TCF7L2) gene is associated with an increased risk of gestational diabetes mellitus. Diabetologia 2007, 50(5):972-979.

14. Freathy RM, Weedon MN, Bennett A, Hypponen E, Relton CL, Knight B, Shields B, Parnell KS, Groves CJ, Ring SM, et al.: Type 2 diabetes TCF7L2 risk genotypes alter birth weight: a study of 24,053 individuals. Am J Hum Genet 2007, 80(6): I| 150-1 | 61 .

15. Pulizzi N, Lyssenko V, Jonsson A, Osmond C, Laakso M, Kajantie E, Barker DJ, Groop LC, Eriksson JG: Interaction between prenatal growth and high-risk genotypes in the development of type 2 diabetes. Diabetologia 2009, 52(5):825-829.

16. Cauchi S, Meyre D, Choquet H, Deghmoun S, Durand E, Gaget S, Lecoeur C, Froguel P, Levy-Marchal C: TCF7L2 rs7903 I 46 variant does not associate with smallness for gestational age in the French population. BMC Med Genet 2007, 8:37.

17. Geelhoed JJ, Mook-Kanamori DO, Witteman JC, Hofman A, van Duijn CM, Moll HA, Steegers EA, Hokken-Koelega AC, Jaddoe VW: Variation in the IGFI gene and growth in foetal life and infancy. The Generation R Study. Clin Endocrinol (Oxf) 2008, 68(3):382-389.

18. Ong KK, Ahmed ML, Emmett PM, Preece MA, Dunger DB: Association between postnatal catch-up growth and obesity in childhood: prospective cohort study. Bmj 2000, 320(7240):967-97I.

19. Fall CH, Sachdev HS, Osmond C, Lakshmy R, Biswas SD, Prabhakaran D, Tandon N, Ramji S, Reddy KS, Barker DJ, et al.: Adult metabolic syndrome and impaired glucose tolerance are associated with different patterns of BMI gain during infancy: Data from the New Delhi Birth Cohort. Diabetes care 2008, 31 (12):2349-2356.

20. Jaddoe VW, Bakker R, van Duijn CM, Heijden AJ van der, Lindemans J. Mackenbach JP, Moll HA, Steegers EA, Tiemeier H, Uitterlinden AG, et al:: The Generation $\mathbf{R}$ Study Biobank: a resource for epidemiological studies in children and their parents. Eur J Epidemiol 2007, 22( ( 2):917-923.

21. Jaddoe VW, van Duijn CM, Heijden AJ van der, Mackenbach JP, Moll HA, Steegers EA, Tiemeier H, Uitterlinden AG, Verhulst FC, Hofman $A$ : The Generation $\mathbf{R}$ Study: design and cohort update until the age of 4 years. Eur J Epidemiol 2008, 23(I2):80I-8II.

22. Verburg BO, Steegers EA, De Ridder M, Snijders RJ, Smith E, Hofman A, Moll HA, Jaddoe VW, Witteman JC: New charts for ultrasound dating of pregnancy and assessment of fetal growth: longitudinal data from a population-based cohort study. Ultrasound Obstet Gynecol 2008, 3 I (4):388-396.

23. Routine ultrasound screening in pregnancy: protocol RCOG. RCOG Press London, UK; 2000.

24. Hadlock FP, Harrist RB, Carpenter RJ, Deter RL, Park SK: Sonographic estimation of fetal weight. The value of femur length in addition to head and abdomen measurements. Radiology 1984, I 50(2):535-540.

25. Fredriks AM, van Buuren S, Burgmeijer RJ, Meulmeester JF, Beuker RJ, Brugman E, Roede MJ, Verloove-Vanhorick SP, Wit JM: Continuing positive secular growth change in The Netherlands 19551997. Pediatr Res 2000, 47(3):316-323.

26. Sas $T$, de Waal W, Mulder P, Houdijk M, Jansen M, Reeser $M$, Hokken-Koelega A: Growth hormone treatment in children with short stature born small for gestational age: 5-year results of a randomized, double-blind, dose-response trial. $J$ Clin Endocrinol Metab 1999, 84(9):3064-3070.

27. Usher R, McLean F: Intrauterine growth of live-born Caucasian infants at sea level: standards obtained from measurements in 7 dimensions of infants born between 25 and 44 weeks of gestation. J Pediatr 1969, 74(6):901-910.

28. Roede MJ, Wieringen JC: Growth diagrams 1980: Netherlands third nation-wide survey. Tijdschr Soc Gezondheidsz 1985, 63(Suppl): $1-34$.

29. SAS/STAT 9.2 User's Guide: The MIXED Procedure. Cary, North Carolina, U.S.A.: SAS Publishing; 2009.

30. Littell RC, Henry PR, Ammerman CB: Statistical analysis of repeated measures data using SAS procedures. J Anim Sci 1998, 76(4):|2|6-|23|.

31. Davey Smith G, Ebrahim S: What can mendelian randomisation tell us about modifiable behavioural and environmental exposures? Bmj 2005, 330(7499): I076-1079.

32. Bennett AJ, Sovio U, Ruokonen A, Martikainen $\mathrm{H}$, Pouta A, Hartikainen AL, Franks S, Elliott $P$, Jarvelin MR, McCarthy MI: No evidence that established type 2 diabetes susceptibility variants in the PPARG and KCNJII genes have pleiotropic effects on early growth. Diabetologia 2008, 5 I(I):82-85.

33. Freathy RM, Bennett AJ, Ring SM, Shields B, Groves C], Timpson NJ, Weedon MN, Zeggini E, Lindgren CM, Lango H, et al:: Type 2 diabetes risk alleles are associated with reduced size at birth. Diabetes 2009, 58(6): | 428-| 433.

34. Hokken-Koelega AC, De Ridder MA, Lemmen RJ, Den Hartog H, De Muinck Keizer-Schrama SM, Drop SL: Children born small for gestational age: do they catch up? Pediatr Res 1995, 38(2):267-27I.

\section{Pre-publication history}

The pre-publication history for this paper can be accessed here:

\section{http://www.biomedcentral.com/1471-2350/10/67/pre} pub
Publish with Biomed Central and every scientist can read your work free of charge

"BioMed Central will be the most significant development for disseminating the results of biomedical research in our lifetime."

Sir Paul Nurse, Cancer Research UK

Your research papers will be:

- available free of charge to the entire biomedical community

- peer reviewed and published immediately upon acceptance

- cited in PubMed and archived on PubMed Central

- yours - you keep the copyright

Submit your manuscript here:

http://www.biomedcentral.com/info/publishing_adv.asp
BioMedcentral 